\title{
OS DESLOCAMENTOS TEMPORAIS E A APRENDIZAGEM DA HISTÓRIA NOS ANOS INICIAIS DO ENSINO FUNDAMENTAL
}

\author{
Magda Madalena Tuma* \\ Marlene Rosa Cainelli* \\ Sandra Regina Ferreira de Oliveira ${ }^{* * *}$
}

\begin{abstract}
RESUMO: Apresentamos neste artigo a análise da progressão do conhecimento no sentido da complexidade do pensamento histórico, com ênfase nos deslocamentos temporais. Situamos nossa investigação no processo de entendimento do aluno quanto aos deslocamentos temporais, o que nos aproximou do constituído e/ ou em constituição pela criança em termos de pensamento histórico perante a história ensinada.

Palavras-chave: Noções de tempo. Educação histórica. Ensino e aprendizagem.
\end{abstract}

\section{DISLOCATIONS IN TIME AND HISTORY LEARNING IN THE FIRST YEARS OF ELEMENTARY SCHOOL}

ABSTRACT: This work analyzes the knowledge progression of first grades students towards the complexity of historical thought with an emphasis on dislocations in time. Classroom situations and children's production made us understand their constituted and or/under construction representations of dislocation in time,

* Doutora em Educação e professora do Departamento de Educação da Universidade Estadual de Londrina (UEL).E-mail: mtuma@sercomtel.com.br

** Doutora em História Social e professora do Departamento de História da UEL. E-mail: cainelli@uel.br

*** Doutora em Educação e professora do Departamento de Educação da UEL. E-mail: sandra.oliveira@uel.br 
Os deslocamentos temporais e a aprendizagem da história nos anos iniciais...

which, in turn, help us understand the child's historical thinking process within the context of the History taught in school.

Key words: Time slight knowledge. History education. Teachinglearning.

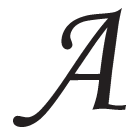

$s$ reflexões aqui apresentadas são resultantes de pesquisas ${ }^{1}$ cujo objetivo é construir referências teóricas e metodológicas para o ensino de História nos anos iniciais do ensino fundamental, a partir dos pressupostos da educação histórica. As pesquisas ancoradas nesta perspectiva educativa destacam o processo de cognição histórica por meio de investigação "qualitativa, descritiva, buscando através da análise indutiva sistemática a compreensão de ideias dos sujeitos acerca da História como explicação, evidência, objetividade, narrativa" (Barca, 2007, p. 37).

Uma das atividades realizadas pelos alunos no ano de 2007 foi a visita a alguns pontos históricos e/ou turísticos da cidade de Londrina. Um desses locais é denominado de "Marco Zero", monumento construído em dezembro de 1984, no cinquentenário da cidade, referenciando o local da chegada da primeira caravana de colonizadores, em 1929. Trata-se de um bloco de concreto, contendo uma placa com dizeres referendando que, naquele local, a primeira caravana de colonizadores marcou as terras compradas pela Companhia de Terras Norte do Paraná, "iniciando" o que viria a ser a cidade de Londrina.

No término do ano letivo, aplicou-se uma avaliação em forma de questóes sobre os assuntos trabalhados durante o ano e as respostas formuladas pelos alunos a uma destas questões - O que é Marco Zero? direcionaram os caminhos da pesquisa para o ano seguinte: a compreensão dos alunos sobre o que é monumento histórico. Algumas respostas resvalaram para a compreensão possível a partir do significado aferido às palavras: é um homem (relação entre a palavra "marco" como nome de pessoa).

Ao analisarmos as respostas para a questão "O que é o Marco Zero?", nos deparamos com o fato de que os alunos não consideravam os acontecimentos que deram historicidade ao local e nem o tempo de existência do monumento. A perspectiva do tempo permanecia congelada, ora no período de fundação da cidade (1934), ora na época de construção do monumento (1984). O tempo decorrido entre um 
acontecimento e outro (a duração) não aparecia na construção das ideias históricas apresentadas pelos alunos. Entendemos que, para aprenderem sobre o conceito de monumento, os alunos, entre outras noções, precisariam estabelecer relações entre as diversas temporalidades que, em nossa concepção, estariam presentes nos monumentos em si, por estes possibilitarem representações que são reinterpretadas a partir da leitura contemporânea.

A partir desse contexto, elaboramos as atividades a serem desenvolvidas no ano de 2008 , tendo por meta a progressão do conhecimento histórico dos alunos acerca do conceito de monumento. A progressão do conhecimento histórico, neste caso, relaciona-se diretamente com o desenvolvimento no aluno da capacidade de realizar leituras do passado, elaborando indagações sobre o assunto estudado. Dessa forma, a intenção era construir propostas metodológicas que propiciassem aos estudantes:

- reverem seus conhecimentos sobre o Marco Zero, por meio do levantamento de ideias prévias, do trabalho com imagens e textos cujo conteúdo favorecesse e induzisse o aluno a mudanças frente ao conhecimento do tema em questão;

- compararem suas ideias prévias com os saberes elaborados após o trabalho com os documentos, aliados às discussões, comparações e demais atividades desenvolvidas em sala de aula;

- elaborarem uma narrativa, explicitando os conhecimentos adquiridos.

Consideramos o conceito de monumento como uma ideia estruturante para o conhecimento histórico porque, ao compreender o que são e porque são construídos estes espaços de memória, o sujeito pode consolidar possibilidades cognitivas de generalização para outros estudos. O que denominamos por conceito estruturante aproxima-se do que Barca (2007, p. 26) define por "ideias de segunda ordem" que nos remetem a compreender "como os sujeitos concebem o conhecimento histórico".

No entanto, ainda utilizando-nos da contribuição da autora, não se trata aqui de propor um trabalho focado somente nas ideias de segunda ordem, relegando os conceitos substantivos, entendidos como o 
Os deslocamentos temporais e a aprendizagem da história nos anos iniciais...

saber elaborado acerca de determinados assuntos que podem englobar "noções gerais, como por exemplo, revolução ou economia, ou noçóes particulares, relativas a um contexto específico no espaço e no tempo, como a Independência do Brasil ou a Revolução do 25 de Abril em Portugal” (idem, ibid.). Para Barca:

(...) apesar da ênfase colocada no desenvolvimento de ideias de segunda ordem, tais conceitos substantivos não podem ser desvalorizados, pois constituem-se, simultaneamente, como matéria prima e resultado desse pensamento ao nível epistemológico. (Op. cit., p. 26-27)

Para Cooper e Dilek (2004), não existe uma definição única para conceitos históricos. Há conceitos que se modificam conforme as organizações das sociedades humanas, como a ideia de poder, de conflito. Outros conceitos não podem ser compreendidos como exclusivamente históricos, mas são importantes para a construção do conhecimento histórico, como o conceito de comércio.

Considerando as assertivas apresentadas por Barca, Cooper e Dilek, compreendemos que o trabalho com o conceito de monumento nos possibilitaria adentrar no nível epistemológico do conhecimento histórico. Dessa forma, as atividades foram encaminhadas, entendendo "monumento" como uma noção fundamental para compreensão de qualquer conteúdo histórico que tenha como objetivo discutir sobre a preservação de memória em espaços públicos.

Intentamos levar o aluno a compreender o que é um monumento no processo de relação histórica entre passado, presente e futuro. Esse conhecimento deveria atingir um patamar de entendimento, possível de ser generalizado para todas as situações nas quais, ao se deparar com um objeto construído em um determinado presente, a partir de uma leitura do passado e com uma intencionalidade posta para o futuro, o sujeito fosse capaz de dialogar refletidamente com estas temporalidades.

Sabemos das dificuldades de se trabalhar com este nível de explicação para alunos de terceira ou quarta série do ensino fundamental (entre nove e dez anos). Portanto, para avançarmos no trabalho sobre o conceito de monumento, nesta perspectiva, precisávamos conhecer como os alunos realizavam deslocamentos temporais. Conforme já explicitamos, partimos da hipótese de que a compreensão do conceito 
de monumento é perpassada por deslocamentos temporais. Planejamos o trabalho em duas etapas: acompanhamento dos deslocamentos temporais possíveis a partir da ficção, com recurso imagético, para o qual utilizamos o filme De volta para o futuro; e sem recurso imagético, trabalhando com a interpretação de uma crônica, por nós intitulada de "Neto Lunar" (Bonassi \& Marinho, 1999). Numa segunda etapa, trabalhamos com análise de fontes (escritas e imagéticas) sobre o "Marco Zero", o monumento em questão. Em todas as etapas do trabalho, priorizamos encaminhamentos metodológicos que valorizassem a postura investigativa nos alunos, potencializando o diálogo entre professor/aluno e alunos/alunos. Neste texto, apresentaremos as reflexões realizadas a partir do trabalho com o filme De volta para of futuro, com foco nas noções de tempo.

Em nosso entendimento, a busca de recursos metodológicos no campo da ficção não cumpre a função de ilustrar um conteúdo trabalhado, mas de oportunizar a presença de situações variadas, para que, na elaboração de narrativas, as crianças, diante de diferentes intencionalidades, percebam as múltiplas relaçóes de causa e efeito que se combinam no desenrolar da trama, compreendendo a ideia do autor, o que este quis transmitir, para, na socialização, perceberem entre eles as diferentes percepçôes sobre o que viram, leram, ouviram.

Cooper (2002) aponta em seus estudos que as crianças trafegam entre diferentes pontos de vista quando são solicitadas para diferentes reconhecimentos, tendo por base suas experiências prévias. Em nosso caso, elas tiveram a oportunidade de comparar elementos socioculturais e históricos em diferentes contextos temporais, inclusive com projeçōes para o futuro, mas contendo elementos que possibilitavam ir além da própria experiência, no reconhecimento de diferenças e semelhanças, assim como de mudanças e permanências.

No que se refere à ficção, Ricoeur (1995, p. 10) nos traz a distinção entre narrativa histórica e ficção quando designa o "termo ficção para as criaçôes literárias que ignoram a ambição, característica da narrativa histórica, de constituir uma narrativa verdadeira" ou que tem a "pretensão à verdade". Nesse sentido, fizemos a proposição que crianças da faixa etária entre 9 e 10 anos elaborassem narrativas em situação de contato com o filme de ficção De volta para o futuro, partindo do entendimento de que este possibilitaria a expressão de representaçôes 
Os deslocamentos temporais e a aprendizagem da história nos anos iniciais...

infantis, sem vínculo direto com um saber escolarizado, no caso, a História.

O uso do filme, como uma estratégia possível para a investigação de como a criança entende os deslocamentos temporais, se insere em nossas pesquisas ao partimos do pressuposto de que, para compreender o sentido do conhecimento histórico, é necessário à criança o entendimento sobre o historiador como uma pessoa de um determinado tempo. Pessoa que produz conhecimento investigando o passado, que contém elementos relacionados ao presente que vive. As noções dominadas pelo historiador, em seu tempo presente sobre o que foi "o futuro" daqueles que estão no "passado" e que adquiriram a condição de objeto de sua pesquisa, o colocam em posição vantajosa. Mas esta condição não possibilita a ele prescindir do deslocamento temporal (presente, passado e futuro), tanto em sua perspectiva como na daqueles que estão situados no passado. A este processo de compreensão que é complexa, mas necessária à criança, ainda inserimos as fontes para a elaboração de narrativa sobre este passado que seria, em última instância, o conhecimento histórico ensinado.

Entendemos que os deslocamentos temporais nos auxiliam na identificação das permanências e rupturas em uma análise comparativa. No entanto, notamos em nossa pesquisa que no trabalho em sala de aula uma abordagem comparativa, na maioria das vezes, acaba não focando o deslocamento temporal, mas sim o presente de cada tempo, como acontece quando solicitamos que os alunos apresentem as permanências e rupturas entre situações do passado e do presente. Nesse sentido, ainda que seja uma análise comparativa que pode propiciar o diálogo temporal entre passado-presente, muitas vezes, o aluno permanece apenas na descrição dos elementos perceptíveis no passado em relação aos de hoje. É como se organizasse dois cenários estáticos para uma ação comparativa propiciada pelo diálogo entre diferentes temporalidades, mas de forma linear e em uma dada sequência: passado-presente, perdendo-se no contexto uma das categorias fundamentais para a compreensão do tempo: a duração.

A duração contém uma condição que traz em sua ausência a não compreensão das diferentes temporalidades, conforme propõe Braudel (2004) - tempo da estrutura, da conjuntura e do acontecimento -, assim como levará à perda na estruturação da narrativa da possibilidade de 
articulação não só entre as diferentes temporalidades, mas também do ritmo estruturado pela duração. É esta a oportunidade de trafegar pelo tempo que geralmente é sonegada da criança, que fica apenas com levantamento de dados relativos ao presente e ao passado, ao não ter como atividade didática, ainda que minimamente, a construção da narrativa.

É neste movimento de reconhecimento dos ritmos da história que teremos a densidade do que se pretende compreender historicamente, o que não prescinde das relações causais de forma não sincrônica e contínua, conforme muitos buscam para sua acomodação e sossego. O que é favorecido na descontinuidade é que os "acontecimentos não se depositam (...) ao longo de uma duração como ganhos diretos e naturais" (Bachelard, 1994, p. 51).

Nesta perspectiva, selecionamos o filme pela possibilidade de aproximação das crianças a determinados conceitos e/ou situações que não estão propriamente alocados na área do conhecimento histórico, mas que podem dar suporte para reflexões sobre esse conhecimento, estabelecendo diálogos que revelem suas interpretações e percepçôes sobre a ficção e a realidade.

Os primeiros diálogos estabelecidos em sala de aula com os alunos se relacionaram ao nome do filme: De volta para o futuro. Indagamos: “é possível voltar para o futuro?". As respostas recebidas enquadram-se em duas perspectivas: (a) a que transita entre a ficção e a realidade, pautada em uma perspectiva de futuro na qual o homem construiria uma máquina do tempo, tornando possível estes deslocamentos temporais; neste tipo de resposta, ainda que no campo ficcional onde tudo é possível, pudemos identificar relações de deslocamentos temporais, pois é necessário imaginar ficcionalmente um espaço para onde ir: o futuro. (b) A perspectiva na qual o tempo (futuro) está diretamente relacionado ao espaço e aos verbos que indicam locomoção (ir, voltar) - duas das crianças responderam: "dá para voltar para o passado porque ele já passou, não dá para voltar ao futuro, pois se não aconteceu não dá para voltar, se fosse para o futuro teria que ir e não voltar, não dá para voltar para o futuro porque ainda não aconteceu”.

Estas respostas indicam a relação temporal concretizada nos tempos verbais da narrativa. É na narrativa que a temporalidade se concretiza e 
Os deslocamentos temporais e a aprendizagem da história nos anos iniciais...

onde se possibilita a elaboração pelos alunos de relaçóes entre o passado e o futuro, ancorados na concepção de lugar ou lugares. Relacionar tempo a lugar possibilitou aos alunos a construção de referenciais para a compreensão de questão abstrata, que vem acompanhada de uma "pegadinha semântica", visto que o verbo voltar é indicativo explícito de retorno e a palavra futuro, do que ainda está por vir.

É importante ressaltar a complexidade de nossa intenção relacionada ao fato de que, nas atividades organizadas e orientadas com base no filme, buscamos a interpretação de como se articula o pensamento da criança sobre os deslocamentos temporais, a causalidade, os sujeitos históricos e as fontes históricas em situações didáticas de discussões; elaboração de uma linha do tempo e de narrativas.

O desafio que nos propomos está no fato de que as crianças se deparariam com diferentes temporalidades (presente, passado e futuro), tanto de sua vida como da dinâmica do filme. Estas diferentes temporalidades apareciam no filme, contrapondo diferentes duraçóes em relação ao ritmo das ações humanas, em contexto onde há visíveis sinais de mudanças (tanto no passado e presente dos personagens, quanto em relação à realidade do aluno), além da aceleração temporal trazida pelo deslocamento.

Reconhecendo nossa ambição, prosseguimos trocando ideias com os alunos para conhecermos como imaginavam a sociedade no ano de 1985. Logo no início, em consenso, explicaram que se tratava de um filme antigo: "tem 23 anos" (em 2008). À pergunta sobre como seria esta sociedade há 23 anos, obtivemos respostas com base em evidências trazidas por elementos materiais e em indicações nas quais apontavam que: a roupa era diferente da nossa; o cabelo das pessoas antigas eram penteados para trás; as calças seriam de tergal e estariam na altura do umbigo; as pessoas seriam mais civilizadas, no modo de falar e comer; as pessoas tinham que casar... Indagados sobre o porquê deste pensamento, responderam que seus pais contaram ou então que viram na televisão. Nas respostas, sempre tentaram atribuir ao passado características que os colocavam em um tempo diferente do presente, expressando a necessidade de demarcar o passado como "outro tempo", um tempo diferente daquele onde vivem. Demarcar essas diferenças pode, em primeira análise, ser muito mais importante do que relacionar o tempo passado ao tempo de onde estão falando. 
Conforme já apontaram pesquisas anteriores (Oliveira, 2003; Cainelli \& Tuma, 2009), o uso de elementos cronológicos que possibilitariam encontrar referenciais no tempo passado, por exemplo, no "tempo do meu avô", não acontece no primeiro momento da análise que o aluno faz sobre como seria tal tempo. Mesmo reconhecendo em nossa investigação a demanda da ampliação de maior entendimento sobre o pensamento das crianças em relação à temporalidade e ao conhecimento histórico, arriscamos afirmar que as crianças buscam imprimir ao "presente" uma diferenciação em relação à sociedade de outros tempos, destacando a modernidade da atualidade para a demarcação de diferenças em relação ao tempo passado.

Ao final da apresentação do filme, sentamos em roda para conversarmos sobre o que tinham entendido e, nestes diálogos, obtivemos variadas percepçóes. Optamos nesta análise por nos determos nas respostas relacionadas aos deslocamentos temporais ocorridos entre 19851955-1985.

Pelos diálogos com os alunos, percebemos que compreendem e acompanham sem dificuldades os deslocamentos temporais que ocorrem no filme, o que podemos notar na narrativa de um dos alunos: "Ele [Marty] está em 1985 e faz uma máquina do tempo e volta para 1955; ele [Marty] foi para o passado porque tava fugindo e no final ele foi para o futuro; para Marty, 1985 é presente e para nós é muito passado". Também o entendimento de que pai e filho ficaram com a mesma idade, "porque a idade do menino ficou a mesma e a do pai mudou", aparece nas narrativas. Em tal conclusão, identificam o deslocamento temporal de Marty e a permanência do pai em seu próprio tempo. Eles reconhecem neste personagem a diferença entre as fases da vida no que se refere ao tempo passado e o presente. O reconhecimento da permanência da "torre, praça, escola, diretor da escola" e das transformaçōes apontadas comparativamente - "a escola em 1955 é limpinha, já em 1985 é suja; o skate era mais quadrado; o pai era mais jovem; o tio era bebê..." - se configura como parte das análises possíveis pelas crianças desta faixa etária.

No intento de chamar a atenção para a questão dos monumentos, colocamos em destaque a cena na qual a senhora pede ajuda para preservar o relógio da torre. A ideia representada no filme foi compreendida pelas crianças, que explicaram, nas verbalizaçóes/narrativas, 
Os deslocamentos temporais e a aprendizagem da história nos anos iniciais...

a situação como aquela em que: "a mulher quer preservar o relógio do jeito que está, parado; que é a mesma hora que o raio caiu, $10 \mathrm{~h} 04$ min" (em 1955). Indagados se concordavam com a ideia de preservação do relógio do jeito que estava, responderam: "não pode mudar o relógio porque é patrimônio".

Para a sistematização da aprendizagem sobre os deslocamentos temporais propiciados a partir do filme e das discussões realizadas e para levar o aluno a exercitar a sua imaginação histórica, solicitamos que representassem o filme em uma linha do tempo, acrescentando a questão: como seria a vida de Marty em 2008, ou seja, no tempo presente? Tal proposta possibilitaria reconhecer como compreenderam o filme e como fariam suposições, visando deslocamentos temporais que exigiam a inserção de seu próprio tempo.

24 alunos realizaram esta atividade, sendo que na análise do material verificamos que 23 alunos produziram texto ou desenho relacionados ao enredo do filme. Em outras palavras, demostraram que entenderam a narrativa trazida pelo filme como ficção, no que se refere aos deslocamentos temporais.

$\mathrm{Na}$ representação gráfica da linha do tempo, nos chamou a atenção a temporalidade da narrativa que se sobrepôs à organização cronológica. Na maioria dos trabalhos, a sequência da linha do tempo é aquela apresentada na narrativa do filme. Estas questôes foram pensadas considerando que propiciariam na operação cognitiva as relações com o tempo passado, com base em dados cronológicos - anos e idades - e a partir do seu tempo presente. A reconstrução do tempo passado, ao ser articulado por datas (2008-1985-1955), marca três tempos de diferentes realidades: a do tempo presente do aluno (2008), a da produção do filme (1985) e da temporalidade apresentada no filme (1985 e 1955), exigindo um raciocínio que retira os alunos da condição de análise espontânea e os insere na necessidade de uma reconstrução temporal de eventos de "maneira metódica". Eles nos indicaram que não trabalharam apenas com o apoio em datas, mas também considerando as situaçóes geradas pelos deslocamentos temporais para os personagens, o que remetia a contextos diferenciados que se imbricavam, como é o caso do "desaparecimento de personagens da fotografia de 1985".

Foi interessante perceber que, entre os dezesseis alunos que apresentaram narrativas sobre 1955 e 1985, seis deles restringiram-se a 
apresentar o que aconteceu no filme, sem elaborar nada relacionado às suposições sobre a situação de Marty em 2008. Este fato precisa ser destacado porque se relaciona à imaginação histórica não exercitada e à forma como os alunos compreendem as aulas de História, ou seja, como eventos estanques, isolados entre si, representado uma "verdade" inquestionável. Exemplificamos a presença desta concepção na resposta formulada por um aluno à indagação feita durante as discussões: $\mathrm{O}$ que está escrito no livro de História é verdade?: "Tudo que está no livro é verdade. Se o livro é de história está certo. As histórias do livro de português não são verdades".

Ainda que nossos elementos sejam insuficientes para adentrar em uma análise sobre esta rigidez atribuída ao entendimento em relação ao livro didático, ou seja, a "posse sobre a verdade do passado" numa aula de História, cabe-nos propor a indagação: que lugar o futuro tem nas aulas de História? Aqueles que "ousaram" trazer o futuro para a linha do tempo formularam hipóteses de que Marty teria se casado com sua namorada e teria filhos, teria casa e carro bonito. Para eles, a mudança possível ou as probabilidades para o futuro ainda estão atreladas aos elementos da realidade sociocultural onde estão situados e não como elaborações onde a relatividade temporal é inserida. A continuidade histórica, quando é considerada (na relação do presente com o passado e com projeçóes para o futuro), demonstra apego aos elementos visíveis trazidos pelas experiências, no caso, as trazidas pelo filme, que apresenta um "happy end" onde aparecem os elementos citados.

Este movimento exigiria um raciocínio temporal que retiraria os alunos da condição de análise espontânea e os levariam a uma reconstrução temporal de eventos de "maneira metódica", pois não teriam como trabalhar apenas com o apoio em datas, mas também com situaçóes de personagens que exigem deslocamentos temporais ao remeter a contextos diferenciados que se imbricam, como é o caso do "desaparecimento de personagens da fotografia de 1985". Além disso, colocaria as crianças em exercício de interpretação que paulatinamente auxiliaria na ultrapassagem da posição de "observador inconsciente" (Matozzi, 1998, p. 38-39), pois é solicitada à criança a elaboração de explicação que contemplaria a "reconstrução do passado" não de forma estática, mas sim "entre passados".

O trabalho com o filme propiciou-nos entender como os alunos transitavam por diferentes temporalidades, assim como auxiliou-nos no 
Os deslocamentos temporais e a aprendizagem da história nos anos iniciais...

levantamento de suas ideias prévias sobre patrimônio, preservação, memórias coletivas, ideias estas diretamente relacionadas ao conceito de monumento.

Recebido em junho de 2009 e aprovado em novembro de 2009.

\section{Nota}

1. Projeto de pesquisa financiado pelo CNPq (Edital de Ciências Humanas/2009) e pela Fundação Araucária (Edital de Pesquisa/2009).

\section{Referências}

BACHELARD, G. A dialética da duração. São Paulo: Ática, 1994.

BARCA, I. Investigação em educação histórica: possibilidades e desafios para a aprendizagem histórica. In: Atas das VI Jornadas Internacionais de Educação Histórica: Perspectivas de Investigação em Educação Histórica. v. 1. Curitiba: UTFPR, 2007. p. 26-42.

BONASSI, F.; MARINHO, C. Vida da gente. São Paulo: Formato, 1999.

BRAUDEL, F. Gramática das civilizações. São Paulo: Martins Fontes, 2004 .

CAINELLI, M. Educação histórica: perspectiva de aprendizagem da história no ensino fundamental. Educar em revista, Curitiba, n. Especial, p. 57-73, 2006.

CAINELLI, M.; TUMA, M. História e memória na construção do pensamento histórico: uma investigação em educação histórica. HISTEDBR on-line, número 34, p. 211-222, 2009.

COOPER, H. Didáctica de la historia en la educación infantil y primaria. Trad. por Pablo Manzano. Madrid: Ministerio de Educación, cultura y Deporte; Ediciones Morata, 2002.

COOPER, H.; DILEK, D. Children's thinking in history: analysis of a history lesson taught to 11 year olds at Ihsan Sungu School, 
Istanbul. International Journal of Historical Learning, Teaching and Research, Londres, v. 4, n. 2/n. 4, jun. 2004. Disponível em <http:// www.heirnet.org/IJHLTR/journal8/8contents.htm>. Acesso em: 1 jul. 2009.

DE VOLTA PARA O FUTURO. Direção: Robert Zemeckis. Produção: Steven Spielberg. Distribuição: Universal Pictures. Estados Unidos, 1985. 116min.

MATOZZI, I. A história ensinada: educação cívica, educação social ou formação cognitiva. O Estudo da História, n. 3. Actas do Congresso "O ensino de História: problemas da didáctica e do saber histórico”. Braga, 1998.

OLIVEIRA, S.R.F. O tempo, a criança e o ensino de História. In: Zamboni, E. (Org.). Quanto tempo o tempo tem! Campinas: Alínea, 2003. p. 145-172.

RICOEUR, P. Tempo e narrativa - Tomo II. Campinas: Papirus, 1995. 